\title{
A high-energy, long cycle-life hybrid supercapacitor based on graphene composite electrodes
}

\author{
Bote Zhao, ${ }^{a}$ Dongchang Chen, ${ }^{a}$ Xunhui Xiong, ${ }^{a}$ Bo Song, ${ }^{a}$ Renzong Hu, ${ }^{a}$ Qiaobao Zhang, ${ }^{a}$ \\ Benjamin H. Rainwater, ${ }^{a}$ Gordon H. Waller, ${ }^{a}$ Dongxing Zhen, ${ }^{a}$ Yong Ding, ${ }^{a}$ Yu Chen, ${ }^{a}$ Chong \\ Qu, ${ }^{a}$ Dai Dang, ${ }^{a}$ Ching-Ping Wong $^{a}$ and Meilin Liu ${ }^{a}$ \\ ${ }^{\text {a }}$ School of Materials Science and Engineering, Georgia Institute of Technology, Atlanta, \\ Georgia 30332-0245, United States.
}

\section{Corresponding Author}

*E-mail: meilin.liu@mse.gatech.edu 


\section{ABSTRACT}

Hybrid supercapacitors consisting of a battery-type faradaic electrode/capacitive electrode couple could achieve significantly improved energy density compared to that of the state-of-theart supercapacitors due to the extended voltage window and introduction of a battery-type electrode with high capacity. However, their commercial application is still hampered by lacking of proper electrode materials and structures. Here, a series of $\mathrm{Co}_{\mathrm{x}} \mathrm{Ni}_{1-\mathrm{x}}(\mathrm{OH})_{2}$-reduced graphene oxide (rGO) nanocomposites are derived from a facile process at room temperature using hydrous hydrazine and different ratios of $\mathrm{Co}$ (II) to $\mathrm{Ni}(\mathrm{II})$ to tune the composition and morphology. In particular, an architectural composite electrode consisting of porous $\mathrm{Co}_{\mathrm{x}} \mathrm{Ni}_{1 \text { - }}$ x $(\mathrm{OH})_{2}$ disks wrapped by rGO achieves high capacity, rate capability (743 and $545 \mathrm{C} \mathrm{g}^{-1}$ at $1 \mathrm{~A} \mathrm{~g}^{-}$ ${ }^{1}$ and $20 \mathrm{~A} \mathrm{~g}^{-1}$, respectively), and long cycling life. When coupled with a p-phenylenediamine (PPD)-modified rGO, the resulting hybrid supercapacitor exhibits superior energy densities of 72 and $44 \mathrm{~W} \mathrm{~h} \mathrm{Kg}^{-1}$ at a power density of $797 \mathrm{~W} \mathrm{Kg}^{-1}$ and $16.7 \mathrm{~kW} \mathrm{Kg}^{-1}$, respectively, and excellent

cycling stability for 20,000 cycles at $20 \mathrm{~A} \mathrm{~g}^{-1}$, implying that it is a very promising device for portable power and next-generation energy storage.

\section{KEYWORDS}

graphene, composites, hybrid supercapacitors, hydroxides, organic molecular 


\section{Introduction}

Supercapacitors (or electrochemical capacitors) have attracted intense attention due to their higher power density and longer cycle-life than existing rechargeable batteries [1-4]. They are well suited for applications requiring rapid power delivery and recharging, such as regenerative braking, short-term energy storage, hybrid electric vehicles, large industrial equipment, and portable devices. However, commercially available supercapacitors are still based on activated carbon materials, known as electrical double-layer capacitors (EDLCs), and have much less energy density than rechargeable batteries, which severely limit their potential for many applications [1].

During the past few years, asymmetric/hybrid supercapacitors with much higher energy density than that of EDLCs, due to the extended voltage window and the significantly enhanced capacitance, are considered a promising energy storage device to meet the demands for many emerging applications [5-18]. The term "asymmetric supercapacitors" is suggested by Brousse et al. to be used for the devices with only capacitive/pseudocapacitive electrodes (e.g., $\mathrm{MnO}_{2} /$ graphene//carbon nanotubes [5]) to avoid confusion with "hybrid" devices in-between a supercapacitor and a battery. [19]. Compared to asymmetric supercapacitors, hybrid supercapacitors consisting of a battery-type faradaic electrode (for high energy density) and a capacitive electrode (for high power density and long cycle life) could achieve even higher energy density because the hybridization of these two electrodes can significantly broaden the operating voltage and increase the capacitance of the hybrid capacitor $[20,21]$. The electrochemical performance of hybrid supercapacitors is sensitive to the nature of the electrode materials, which are the key to developing a long cycle-life hybrid supercapacitor with high energy and power density. In a typical hybrid supercapacitor, the capacitive electrode is usually 
activated carbon[11-14, 22] or graphene[15, 18, 23, 24], and the battery-type electrode is lithium intercalation compounds [7, 8] or transition metal compounds[16, 17, 22, 24, 25].

Recently, Ni and/or Co-based oxides/hydroxides have been reported as one of the most promising candidates for battery-type electrodes in hybrid supercapacitors due to their attractive theoretical specific capacity and potentially high rate capability in aqueous electrolyte (e.g., $\mathrm{KOH}$ ). These oxides/hydroxides that were reported as advanced "pseudocapacitive" materials[26-28], have been recently considered as "extrinsic pseudocapacitors" [29] (with other examples including $\mathrm{V}_{2} \mathrm{O}_{5}[29]$ and metal sulfides[30, 31]), which do not exhibit pseudocapacitance but battery-type behavior in the bulk state due to phase transformations during ion storage, but an improved capacitive behavior in nanosize with increased surface area especially at high current density. Now these $\mathrm{Ni}$ and/or Co-based oxides/hydroxides have been termed as battery-type faradaic electrode materials based on their electrochemical behavior in aqueous electrolytes $[2,19,32]$, which have gained significant credence. However, these oxides/hydroxides suffer from relatively poor electronic conductivity, leading to limited rate capability and cycling stability. Growth of these $\mathrm{Ni}$ and/or Co-based oxides/hydroxides on conductive substrates such as carbon fiber paper[27], or nickel foam[33-35] have been demonstrated as an effective approach to improve the electronic conductivity, further resulting in an improved rate capability and cycling performance. Compared to commercial carbon fiber papers and nickel foams, the formation of composites with graphene is preferred. Graphenebased materials have been widely reported with attractive electrical/electrochemical properties [36-41]. The much higher surface area and ultrathin thickness of graphene results in significantly enhanced mass loading of active materials (i.e., $\mathrm{Ni}$ and/or Co-based oxides/hydroxides), and further improved capacity based on the total mass of active materials/conductive substrates. To 
date, numerous efforts have been devoted to engineering the microstructures of $\mathrm{Ni}$ and/or Cobased oxides/hydroxides for improved electrochemical performance[24-26, 42-44]. However, advanced architecture with stable cycling performance as well as high rate capability derived from a facile method is still rarely reported. Porous microstructures in micrometer-size derived from a facile method are significantly preferred for commercial applications.

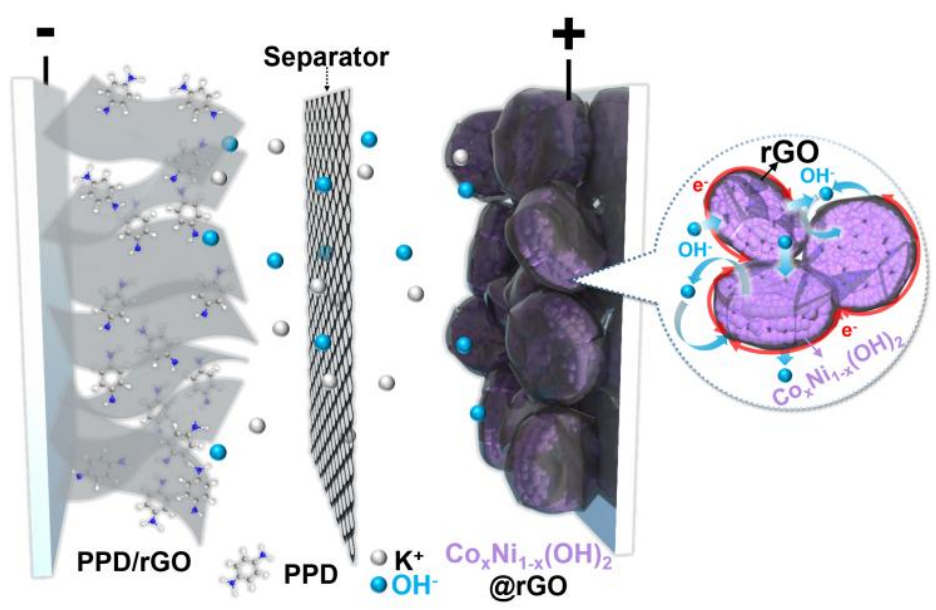

Figure 1. Schematic illustration of the hybrid supercapacitor device with a $\mathrm{Co}_{\mathrm{x}} \mathrm{Ni}_{1-\mathrm{x}}(\mathrm{OH})_{2} @$ reduced graphene oxide ( $\mathrm{rGO}$ ) composite as a battery-type faradaic electrode and a pphenylenediamine (PPD)-modified rGO composite as a capacitive electrode.

In this work, we report our findings on the synthesis and characterization of a series of $\mathrm{Co}_{\mathrm{x}} \mathrm{Ni}_{1-\mathrm{x}}(\mathrm{OH})_{2}$-reduced graphene oxide (rGO) nanocomposites prepared by a facile process at room temperature where hydrous hydrazine was used as the $\mathrm{OH}^{-}$source and reducing agent. Different ratios of initial $\mathrm{Co}(\mathrm{II})$ to $\mathrm{Ni}(\mathrm{II})$ and different amounts of hydrazine have been used to tune the composition and morphology. Specifically, a porous disk-like $\mathrm{Co}_{\mathrm{x}} \mathrm{Ni}_{1-\mathrm{x}}(\mathrm{OH})_{2}$ structure wrapped by rGO was prepared, in which the unique porous structures facilitate rapid access of liquid electrolyte to electrode materials and rGO offers effective electron paths for fast energy 
storage. The resulting composite electrode exhibited a high specific capacity, rate capability, and cycling stability. More importantly, when coupled with a high-performance p-phenylenediaminemodified rGO (PPD/rGO) capacitive electrode, the hybrid supercapacitor (Figure 1) delivered greatly enhanced gravimetric/volumetric energy density and cycle-life compared to those of recently reported advanced hybrid/asymmetric supercapacitors[22-25, 45-49]. The simple preparation process and high performance make the hybrid supercapacitor attractive for a wide variety of applications.

\section{Experimental Section}

Materials synthesis: Graphite oxide was synthesized by a modified Hummers' method [50]. The as-prepared aqueous suspension of graphite oxide was diluted with deionized water under ultrasonication for $5 \mathrm{~h}$ to obtain an exfoliated graphene oxide (GO) suspension $\left(\sim 1 \mathrm{mg} \mathrm{mL}^{-1}\right) .50$ $\mathrm{mL}$ of mixed $\mathrm{Ni}\left(\mathrm{CH}_{3} \mathrm{COO}\right)_{2} \cdot 4 \mathrm{H}_{2} \mathrm{O}$ and $\mathrm{Co}\left(\mathrm{CH}_{3} \mathrm{COO}\right)_{2} \cdot 4 \mathrm{H}_{2} \mathrm{O}$ solution with $30 \mathrm{mmol}$ of total metal ions was poured into a $50 \mathrm{~mL}$ of GO suspension $\left(1 \mathrm{mg} \mathrm{mL}^{-1}\right)$ and stirred for $10 \mathrm{~min}$, and then $1.5 \sim 4.5 \mathrm{~mL}$ of hydrazine monohydrate $\left(\mathrm{N}_{2} \mathrm{H}_{4} 64-65 \%\right.$, reagent grade, $98 \%$, SigmaAldrich) was dropped into the solution, followed by stirring for $36 \mathrm{~h}$ at room temperature. The as-obtained composite was washed repeatedly with deionized water by vacuum filtration until the filtrate had a neutral $\mathrm{pH}$ and the filtrate became colorless. The collected black solids were dried at room temperature in air under fume hood.

By adding $1.5 \mathrm{~mL}$ of hydrazine monohydrate, a series of $\mathrm{Co}_{\mathrm{x}} \mathrm{Ni}_{1-\mathrm{x}}(\mathrm{OH})_{2}-\mathrm{rGO}$ composites with different $\mathrm{Co}^{2+}: \mathrm{Ni}^{2+}$ ratios but fixed total metal ion amount $(30 \mathrm{mmol})$ were prepared and named CNOHa:b (a:b means that the mole ratio of $\mathrm{Co}(\mathrm{II}): \mathrm{Ni}(\mathrm{II})$ in the raw materials). By fixing the initial $\mathrm{Ni}$ (II) to $\mathrm{Co}(\mathrm{II})$ ratio as $1: 1$, the increased amounts of hydrous hydrazine (3.0 and 4.5 
$\mathrm{mL}$ ) were further used to synthesize the $\mathrm{Co}_{\mathrm{x}} \mathrm{Ni}_{1-\mathrm{x}}(\mathrm{OH})_{2}$-rGO nanocomposites, which were named CNOH1:1-II, and CNOH1:1-III, respectively. A pure rGO was also prepared in a similar fashion by using $4.5 \mathrm{~mL}$ of hydrous hydrazine as the reducing agent only without adding $\mathrm{Ni}\left(\mathrm{CH}_{3} \mathrm{COO}\right)_{2} \cdot 4 \mathrm{H}_{2} \mathrm{O}$ or $\mathrm{Co}\left(\mathrm{CH}_{3} \mathrm{COO}\right)_{2} \cdot 4 \mathrm{H}_{2} \mathrm{O}$.

To prepare the PPD/rGO material, $50 \mathrm{mg}$ of GO was dispersed in $35 \mathrm{~mL}$ of deionized water. Then, $54 \mathrm{mg}$ of PPD was dissolved in $15 \mathrm{~mL}$ of deionized water and added into the GO suspension. The mixture was stirred for $30 \mathrm{~min}$ and reacted in a Teflon-lined stainless steel autoclave at $180^{\circ} \mathrm{C}$ for $12 \mathrm{~h}$. After the reaction, the composite was washed repeatedly with deionized water and dried at $55^{\circ} \mathrm{C}$ for $24 \mathrm{~h}$.

Basic characterization: The X-ray diffraction (XRD) patterns were recorded with an X'Pert PRO Alpha-1 X-ray diffractometer. A scanning electron microscope (SEM, LEO 1530) coupled with an energy dispersive X-ray spectrometer (EDX) was used to analyze the morphologies and element distribution/ratio of samples. A high-resolution transmission electron microscope (TEM, FEI G2 Tecnai F30) was used to analyze the microstructures and morphologies of samples. Prior to TEM analysis, the samples were ultrasonically dispersed in ethanol for several hours. The nitrogen adsorption-desorption isotherm of the sample was measured at the boiling point of liquid nitrogen (77 K) using a Micromeritics ASAP 2020 analyzer. Thermogravimetric analysis (TGA) was carried out with an SDTQ-600 (TA Instruments Co.) apparatus in air with a heating rate of $10{ }^{\circ} \mathrm{C} \mathrm{min}^{-1}$. X-ray photoelectron spectroscopy (XPS) was measured on a Thermo KAlpha XPS spectrometer (Thermo Fisher Scientific) equipped with a monochromatic Al-Ka Xray source $(\mathrm{hv}=1468.6 \mathrm{eV})$. Raman spectroscopic measurement was performed using a 
Renishaw RM1000 microspectroscopic system. A He-Ne laser with a wavelength of $633 \mathrm{~nm}$ (Thorlab HRP-170) was applied as excitation laser through a 20x/0.40 objective.

Electrochemical measurement: The electrochemical performances of the as-obtained $\mathrm{Co}_{\mathrm{x}} \mathrm{Ni}_{1}$ ${ }_{x}(\mathrm{OH})_{2}-\mathrm{rGO}$ materials were investigated under a three-electrode configuration in a beaker with a $2 \mathrm{M} \mathrm{KOH}$ aqueous solution as electrolyte at room temperature. $\mathrm{A} \mathrm{Ag} / \mathrm{AgCl}$ electrode prefilled with $4 \mathrm{M} \mathrm{KCl}$ aqueous solution saturated with $\mathrm{AgCl}$ and a Pt mesh electrode were used as the reference and the counter electrodes, respectively. The working electrode was prepared as follows: the $\mathrm{Co}_{\mathrm{x}} \mathrm{Ni}_{1-\mathrm{x}}(\mathrm{OH})_{2}$-rGO materials and Super $\mathrm{P}$ Li powders (TIMCAL Graphite \& Carbon) were ground and sieved through a 170-mesh sieve before using; a free-standing film (5/16 in. in diameter) was made from a mixture of $\mathrm{Co}_{x} \mathrm{Ni}_{1-\mathrm{x}}(\mathrm{OH})_{2}-\mathrm{rGO}$ materials, Super $\mathrm{P} \mathrm{Li}$ and polytetrafluoroethylene (PTFE) at a mass ratio of 85:10:5 with assistance of ethanol; the working electrode was obtained by pressing the free-standing film between two nickel foams $(3 / 8$ in. in diameter). Besides acting as a conductive additive, the Super P Li powders was also used as additive to assist the preparation of free-standing electrode films; it appears that we were unable cast the $\mathrm{Co}_{\mathrm{x}} \mathrm{Ni}_{1-\mathrm{x}}(\mathrm{OH})_{2}$-rGO into a free-standing electrode film without adding Super $\mathrm{P}$ Li powders. The typical mass loading of the active material (i.e., $\mathrm{Co}_{\mathrm{x}} \mathrm{Ni}_{1-\mathrm{x}}(\mathrm{OH})_{2}-\mathrm{rGO}$ ) in the electrode is $2.7 \sim 3.3 \mathrm{mg} \mathrm{cm}^{-2}$. The working electrode was soaked in a $2 \mathrm{M} \mathrm{KOH}$ aqueous solution under vacuum for $>8 \mathrm{~h}$ before the electrochemical measurement.

The electrochemical performances of the hybrid supercapacitor were investigated under a two-electrode configuration in a split test cell (MTI Corporation). The free-standing film mixture of $\mathrm{Co}_{x} \mathrm{Ni}_{1-\mathrm{x}}(\mathrm{OH})_{2}-\mathrm{rGO}$ materials, Super P Li and PTFE at a mass ratio of 85:10:5 was used as the 
positive electrode. The negative electrode was a free-standing film of mixture of PPD/rGO materials and PTFE at a mass ratio of 95:5. Carbon fiber papers (7/16 in. in diameter) were used as current collectors by only physical contact with the working electrode. A $2 \mathrm{M} \mathrm{KOH}$ aqueous solution was used as electrolyte, and a NKK separator (MPF30AC-100, Nippon Kodoshi Corporation, Kochi, Japan) was used as the separator. The electrodes were soaked in the electrolyte solution for approximately $1 \mathrm{~h}$ under vacuum and were assembled in a split test cell under ambient atmosphere. The cell was tightened by 4 nuts and bolts, and was standing for another $9 \mathrm{~h}$ under atmospheric pressure before the electrochemical measurement.

Cyclic voltammograms were recorded on a Solartron electrochemical workstation (Solartron SI 1287 electrochemical interface). The galvanostatic charge/discharge measurements were carried out using an Arbin testing system (BT-2143) at room temperature. At the beginning of the electrochemical measurement, the working electrode or cell was always activated via cyclic voltammetry test at a scan rate of $30 \mathrm{mV} \mathrm{s}^{-1}$ for 5-10 cycles until cyclic voltammograms became relatively stable. The cycling performance of three-electrode system or two-electrode device was carried out after the initial activating process and rate capability testing.

The specific capacity $\left(\mathrm{C} \mathrm{g}^{-1}\right)$ of $\mathrm{Co}_{\mathrm{x}} \mathrm{Ni}_{1-\mathrm{x}}(\mathrm{OH})_{2}-\mathrm{rGO}$ electrode based on the galvanostatic discharge curve was calculated using the following equation:

$$
Q=I \Delta t / m
$$

where $I(\mathrm{~mA})$ is the discharge current, $\Delta t(\mathrm{~s})$ is the discharge time, and $m(\mathrm{mg})$ is the mass of the active material (i.e., $\mathrm{Co}_{\mathrm{x}} \mathrm{Ni}_{1-\mathrm{x}}(\mathrm{OH})_{2}-\mathrm{rGO}$ ). The specific capacity is based on the total mass of the $\mathrm{Co}_{\mathrm{x}} \mathrm{Ni}_{1-\mathrm{x}}(\mathrm{OH})_{2}-\mathrm{rGO}$ composite. 
The mass ratio of positive electrode to negative electrode in the hybrid supercapacitor device was determined to better balance the obtainable charge of the two electrodes $\left(q_{+}=q_{-}\right)$. The charge of the positive electrode $\left(q_{+}\right)$was calculated with that of the negative electrode $\left(q_{-}\right)$based on the cyclic voltammograms acquired from a cell with a three-electrode configuration.

$$
q=\int i m d V / v
$$

where $q(\mathrm{C})$ is the charge, $i\left(\mathrm{~A} \mathrm{~g}^{-1}\right)$ is the current density, $m(\mathrm{mg})$ is the mass of the active material, $V(\mathrm{~V})$ is the voltage, $v\left(\mathrm{mV} \mathrm{s}^{-1}\right)$ is the scan rate, and $\int i \mathrm{~d} V$ is the integral area of the cyclic voltammogram.

To achieve $q_{+}=q_{-}$, the mass ratio of positive electrode active material to negative electrode active material is determined from the following equation:

$$
m_{+}: m_{-}=(j i d V / v)_{-}:(j i d V / v)_{+}
$$

The mass ratio of the positive electrode active material $\left(\mathrm{Co}_{\mathrm{x}} \mathrm{Ni}_{1-\mathrm{x}}(\mathrm{OH})_{2}-\mathrm{rGO}\right)$ to the negative electrode active material (PPD/rGO) was calculated to be 1:2.28 for the hybrid supercapacitor, as determined from the cyclic voltammograms acquired at $10 \mathrm{mV} \mathrm{s}^{-1}$ (Figure 4a) for both electrodes.

The energy density $\left(\mathrm{W} \mathrm{h} \mathrm{kg}^{-1}\right)$ of the hybrid supercapacitor device was calculated based on the galvanostatic discharge curve using the following equation:

$$
E=I \int V d t / 3.6\left(m_{\mathrm{Co}_{x} \mathrm{Ni}_{1-x}(\mathrm{OH})_{2}-\mathrm{rGO}}+m_{\mathrm{PPD} / \mathrm{rGO}}\right)
$$

The constant 3.6 is adopted when the energy density $(E)$ is in $\mathrm{W} \mathrm{h} \mathrm{kg}^{-1}$, the current $(I)$ is in $\mathrm{mA}$, the voltage $(V)$ is in $\mathrm{V}$, the time $(t)$ is in seconds, and the mass $(m)$ is in mg. The mass used in the 
calculation for hybrid supercapacitor device was based on the total mass of $\mathrm{Co}_{\mathrm{x}} \mathrm{Ni}_{1-\mathrm{x}}(\mathrm{OH})_{2}-\mathrm{rGO}$ composite and $\mathrm{PPD} / \mathrm{rGO}$ composite.

The power density $\left(\mathrm{W} \mathrm{kg}^{-1}\right)$ is calculated using the following equation:

$$
P=E / \Delta t
$$

\section{Results and Discussion}

The preparation processes of $\mathrm{Co}_{\mathrm{x}} \mathrm{Ni}_{1-\mathrm{x}}(\mathrm{OH})_{2}$-rGO composites are schematically illustrated in Figure 2a. $\mathrm{Co}(\mathrm{II}) / \mathrm{Ni}(\mathrm{II})$-containing aqueous solution was mixed with $\mathrm{GO}$ suspension, followed by adding $1.5 \mathrm{~mL}$ of hydrous hydrazine, stirring for $36 \mathrm{~h}$ at room temperature. A series of $\mathrm{Co}_{\mathrm{x}} \mathrm{Ni}_{1-\mathrm{x}}(\mathrm{OH})_{2}-\mathrm{rGO}$ composites with different $\mathrm{Co}(\mathrm{II}): \mathrm{Ni}(\mathrm{II})$ ratios were prepared and named CNOHa:b (a:b means that the mole ratio of $\mathrm{Co}(\mathrm{II}): \mathrm{Ni}(\mathrm{II})$ in the raw materials; the actual ratios in the as-prepared samples were also tested by EDX analysis with results shown in Table S1, which were similar to initial ratios by adding $1.5 \mathrm{~mL}$ of hydrous hydrazine). After washing, the morphologies of the as-obtained $\mathrm{Co}_{\mathrm{x}} \mathrm{Ni}_{1-\mathrm{x}}(\mathrm{OH})_{2}$-rGO composites (Figure $\mathrm{S} 1$ ) were very similar, although the degree of aggregation may appear somewhat different. The morphological features are dominated by wrinkled graphene sheets, suggesting that the as-prepared $\mathrm{Co}_{\mathrm{x}} \mathrm{Ni}_{1-\mathrm{x}}(\mathrm{OH})_{2}$ are small nanoparticles, as reflected by the relatively low intensity of X-ray diffraction (XRD) peaks (Figure S2). The XRD patterns of CNOH3:0, CNOH2:1, CNOH1:1, and CNOH1:2 samples were similar with four broad peaks corresponding to $\alpha-\mathrm{Ni}(\mathrm{OH})_{2}$ - and $\alpha-\mathrm{Co}(\mathrm{OH})_{2}$-like structures [51]. No diffraction peak corresponding to metallic Ni or Co was observed. The CNOH0:3 sample without $\mathrm{Co}(\mathrm{II})$ was almost amorphous instead of the $\alpha-\mathrm{Ni}(\mathrm{OH})_{2}$-like structure, which may be attributed to some special reaction with hydrous hydrazine in absence of Co(II). The XRD 
peak intensity of the $\mathrm{CNOH} 3: 0$ sample without $\mathrm{Ni}(\mathrm{II})$ was much lower than those of the CNOH2:1, CNOH1:1, and CNOH1:2 samples. These results suggest that the presence of both $\mathrm{Co}(\mathrm{II})$ and $\mathrm{Ni}$ (II) ions in the alkaline solution (hydrous hydrazine) improves the crystallinity of the hydroxides. The absence of the obvious diffraction peak corresponding to rGO could be attributed to the distinctly reduced layer-to-layer interaction between adjacent graphene sheets
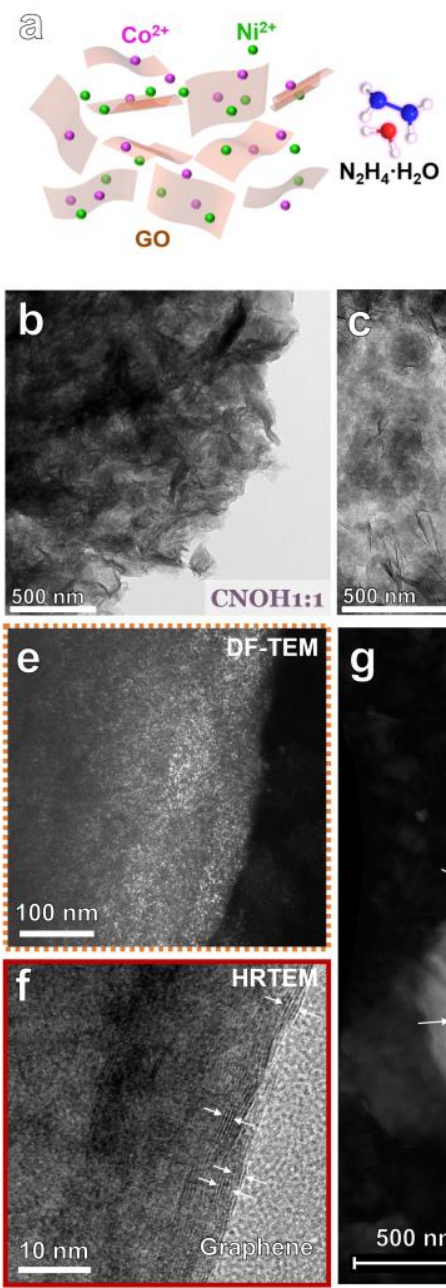

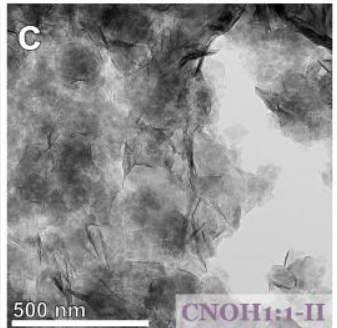

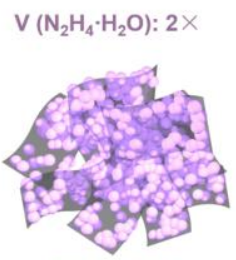

CNOH1:1-II

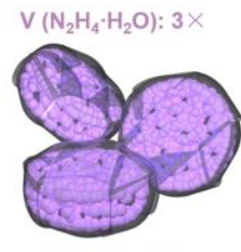

CNOH1:1-III
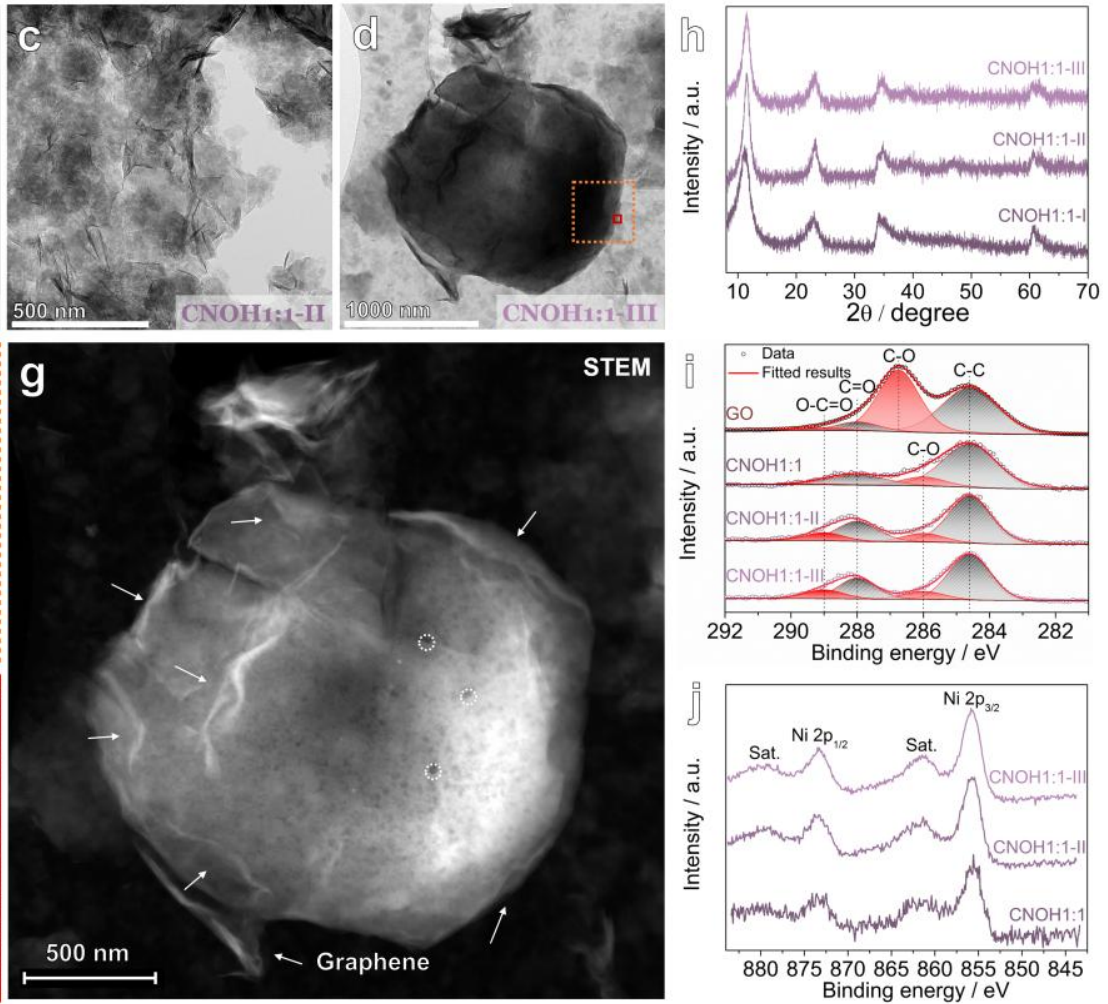

Figure 2. (a) Schematic illustration of the preparation of $\mathrm{Co}_{\mathrm{x}} \mathrm{Ni}_{1-\mathrm{x}}(\mathrm{OH})_{2}-\mathrm{rGO}$ composites via a facile hydrazine-induced process at room temperature. (b, c, d) BF-TEM images of (b) CNOH1:1, (c) CNOH1:1-II, and (d) $\mathrm{CNOH} 1: 1-\mathrm{III}$ (i.e., $\mathrm{Co}_{\mathrm{x}} \mathrm{Ni}_{1-\mathrm{x}}(\mathrm{OH})_{2}-\mathrm{rGO}$ composite; 1:1 means that the mole ratio of $\mathrm{Co}(\mathrm{II}): \mathrm{Ni}(\mathrm{II})$ in the raw materials is $1: 1$; I, II, and III represent the sample prepared 
with different amounts of hydrous hydrazine); (e) DF-TEM, and (f) HRTEM images of CNOH1:1-III obtained from the selected rectangle region with orange border (dotted line), and red border (solid line) in (d), respectively; (g) HAADF STEM image of CNOH1:1-III; the arrows in (f) indicate layered graphene structure; the arrows in (g) indicate the graphene sheet structures, the circles (dotted line) indicate the typical pores in the unique architecture. (h) XRD patterns, (i) XPS spectra of C 1s, and (j) XPS spectra of Ni 2p of as-prepared samples using different amounts of hydrous hydrazine: CNOH1:1, CNOH1:1-II, and CNOH1:1-III; XPS spectrum of C 1s in GO sample was also given in (i); "Sat." in (j) means satellite.

which could be an indication that the surface of rGO was mostly covered by as-formed $\mathrm{Co}_{\mathrm{x}} \mathrm{Ni}_{1}$ ${ }_{x}(\mathrm{OH})_{2}$.

The hydrous hydrazine in the synthesis process plays two key roles: offering $\mathrm{OH}^{-}$for the formation of $\mathrm{Co}_{\mathrm{x}} \mathrm{Ni}_{1-\mathrm{x}}(\mathrm{OH})_{2}$ and acting as the reducing agent for reducing $\mathrm{GO}$. We systematically varied the used amount of hydrous hydrazine to explore the effect on the material properties (Figure 2a). With increasing amount of hydrous hydrazine from 1.5 to $3.0 \mathrm{~mL}$, the morphology of as-obtained sample (named CNOH1:1-II) (Figure S3a) still remained similar, but somewhat looser compared to that of the $\mathrm{CNOH} 1: 1$ sample (Figure $\mathrm{S} 3 \mathrm{~b}$ ). When the amount of hydrous hydrazine was increased to $4.5 \mathrm{~mL}$, many $\mathrm{Co}_{\mathrm{x}} \mathrm{Ni}_{1-\mathrm{x}}(\mathrm{OH})_{2}$ disk-like structures of micrometer-size appeared in the as-prepared sample (named CNOH1:1-III), as shown in Figure S3c. More importantly, it seems that the $\mathrm{Co}_{\mathrm{x}} \mathrm{Ni}_{1-\mathrm{x}}(\mathrm{OH})_{2}$ disks were wrapped by graphene sheets. The Co:Ni ratios in the samples measured by EDX analysis increased from 44:56 for $\mathrm{CNOH} 1: 1$ sample to 65:35 for $\mathrm{CNOH1}: 1-\mathrm{II}$ sample, and 69:31 for $\mathrm{CNOH1} 1$ 1-III sample, respectively, with increasing amount of hydrous hydrazine (Table S1). As seen from the transmission electron microscopy (TEM)/scanning TEM (STEM) images shown in Figure 2b-g, a significant amount of folding 
graphene sheets were observed for the samples. The bright-field (BF)-TEM image of CNOH1:1II sample (Figure 2c) confirmed that it had relatively loose microstructure compared to that of $\mathrm{CNOH} 1: 1$ sample (Figure 2b). Figure 2d presents a typical $\mathrm{Co}_{\mathrm{x}} \mathrm{Ni}_{1-\mathrm{x}}(\mathrm{OH})_{2} @ \mathrm{rGO}$ disk, in which the $\mathrm{Co}_{\mathrm{x}} \mathrm{Ni}_{1-\mathrm{x}}(\mathrm{OH})_{2}$ disk appeared to be wrapped by graphene sheets. Dark-field (DF)-TEM images demonstrate that the as-formed $\mathrm{Co}_{x} \mathrm{Ni}_{1-\mathrm{x}}(\mathrm{OH})_{2}$ in $\mathrm{CNOH} 1: 1-\mathrm{III}$ (Figure 2e), $\mathrm{CNOH} 1: 1-\mathrm{II}$ (Figure S4) and CNOH1:1 (Figure S5) samples were actually ultrafine nanocrystals. These nanocrystals were relatively uniformly distributed in the composites especially for CNOH1:1-II and CNOH1:1. Figure 2f and S6 show two typical high-resolution TEM (HRTEM) images of the border of $\mathrm{Co}_{\mathrm{x}} \mathrm{Ni}_{1-\mathrm{x}}(\mathrm{OH})_{2} @ \mathrm{rGO}$ disk, in which the periodic lattice fringe corresponding to $\mathrm{Co}_{\mathrm{x}} \mathrm{Ni}_{1-}$ ${ }_{x}(\mathrm{OH})_{2}$ phase were wrapped by clear graphene sheets with 3-5 layers. High-angle anular darkfield (HAADF) STEM image (Figure 2g) confirmed that the $\mathrm{Co}_{\mathrm{x}} \mathrm{Ni}_{1-\mathrm{x}}(\mathrm{OH})_{2}$ disk was wrapped by graphene sheets. Importantly, the as-obtained $\mathrm{Co}_{\mathrm{x}} \mathrm{Ni}_{1-\mathrm{x}}(\mathrm{OH})_{2}$ disks were porous with a significant quantity of mesopores from the observation of HAADF STEM (Figure $2 g$ and S7). The porosity of the samples was further analyzed by nitrogen adsorption-desorption measurements, confirming the mesoporosity in CNOH1:1-III sample (Figure S8). Such porous structure would facilitate the access of liquid electrolyte to electrode materials for fast ionic transport while the wrapped graphene sheets promote effective electron transport and current collection.

The phase structures of these as-prepared nanocomposites were almost the same, as reflected by the XRD patterns shown in Figure $2 \mathrm{~h}$. No diffraction peaks corresponding to metallic Ni or Co were observed even when the amount of hydrous hydrazine was increased to 4.5 $\mathrm{mL}$. The character of broad peaks in XRD patterns was consistent with the ultrafine nanocrystal nature as observed by DF-TEM (Figure 2e, S4, and S5). As determined by thermogravimetric analysis (TGA) (Figure S9), the content of $\mathrm{Co}_{\mathrm{x}} \mathrm{Ni}_{1-\mathrm{x}}(\mathrm{OH})_{2}$ in the composite 
increased with increasing amount of hydrous hydrazine from $\mathrm{CNOH} 1: 1$ to $\mathrm{CNOH} 1: 1-\mathrm{II}$ sample and almost remained unchanged for the $\mathrm{CNOH} 1: 1-\mathrm{III}$ sample.

Figure 2i shows X-ray photoelectron spectroscopy (XPS) spectra of C1s in different samples with fitted results. After the synthesis process, the intensity of C-O-type carbon (286.8 $\mathrm{eV}$, including $\mathrm{C}-\mathrm{OH}$ and $\mathrm{C}-\mathrm{O}-\mathrm{C}$ (epoxide groups)) significantly decreased, confirming that the GO was successfully reduced by hydrous hydrazine. The peak shift of C-O-type carbon was attributed to the sharp reduction of C-O-C groups in C-O-type carbon. With increasing amount of hydrous hydrazine, the content of $\mathrm{C}=\mathrm{O}$ - and $\mathrm{O}-\mathrm{C}=\mathrm{O}$-type carbon somewhat increased. This result is anomalous since hydrous hydrazine is a well-known reducing agent. The result may be due to the competition between the formation of metal hydroxide and the reduction of graphene oxide. In the Ni $2 p$ spectra (Figure $2 \mathrm{j})$, expected Ni $2 \mathrm{p}_{1 / 2}(873.3 \mathrm{eV})$ and $\mathrm{Ni} 2 \mathrm{p}_{3 / 2}(855.7 \mathrm{eV})$ signals were observed with two corresponding satellites for all the samples, consistent with that of $\mathrm{Ni}(\mathrm{OH})_{2}[52,53]$ and Ni-Co hydroxide [28]. No Ni $2 \mathrm{p}_{3 / 2}$ peak centered at $\sim 852.6 \mathrm{eV}$ was observed, confirming that no metallic Ni formed under this reducing environment. The Co $2 \mathrm{p}_{3 / 2}$ was centered at $780.8 \mathrm{eV}$ (Figure S10), suggesting the formation of cobalt hydroxide [54]. The spin-orbit splitting value of Co $2 \mathrm{p}_{1 / 2}$ and Co $2 \mathrm{p}_{3 / 2}$ was $15.6 \mathrm{eV}$, and the intensity of the Co $2 \mathrm{p}_{3 / 2}$ satellite line was low, indicating the presence of both $\mathrm{Co}^{3+}$ and $\mathrm{Co}^{2+}$ in these $\mathrm{Co}_{\mathrm{x}} \mathrm{Ni}_{1-\mathrm{x}}(\mathrm{OH})_{2}-\mathrm{rGO}$ samples $[28,52]$. The formation of $\mathrm{Co}_{\mathrm{x}} \mathrm{Ni}_{1-\mathrm{x}}(\mathrm{OH})_{2}-\mathrm{rGO}$ composite was further supported by Raman analysis (Figure S11).

To characterize the electrochemical performance, the as-prepared $\mathrm{Co}_{\mathrm{x}} \mathrm{Ni}_{1-\mathrm{x}}(\mathrm{OH})_{2}-\mathrm{rGO}$ composites were tested using a three-electrode configuration in a $2 \mathrm{M} \mathrm{KOH}$ aqueous solution. Shown in Figure 3a are some typical cyclic voltammetric (CV) curves of $\mathrm{Co}_{\mathbf{x}} \mathrm{Ni}_{1-\mathrm{x}}(\mathrm{OH})_{2}-\mathrm{rGO}$ composite electrodes derived from different $\mathrm{Co}$ (II) to $\mathrm{Ni}$ (II) ratios and $1.5 \mathrm{~mL}$ of hydrous 
hydrazine. While one pair of redox peaks were observed for all samples, the oxidation peak of the as-prepared composite electrodes shifted in the positive potential direction while increasing the initial $\mathrm{Ni}(\mathrm{II})$ content. The $\mathrm{CNOH} 2: 1$ and $\mathrm{CNOH} 1: 1$ samples exhibited the largest integral area, indicating the highest specific capacities. Figure $3 \mathrm{~b}$ shows the galvanostatic chargedischarge curves of the $\mathrm{Co}_{\mathrm{x}} \mathrm{Ni}_{1-\mathrm{x}}(\mathrm{OH})_{2}-\mathrm{rGO}$ composite electrodes at $1 \mathrm{~A} \mathrm{~g}^{-1}$; the electrochemical
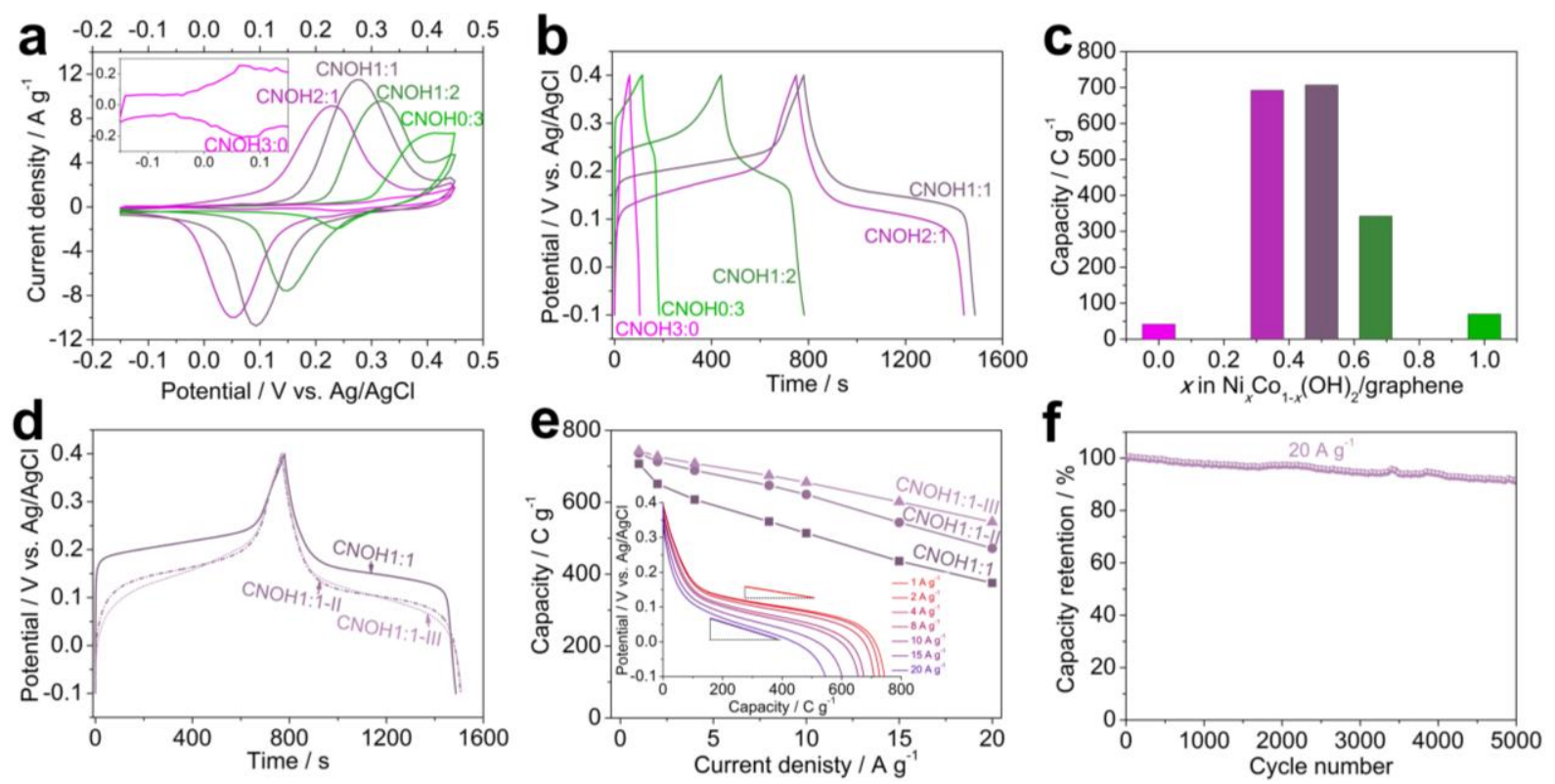

Figure 3. (a) $\mathrm{CV}$ curves at a scan rate of $2 \mathrm{mV} \mathrm{s}^{-1}$, (b) $5^{\text {th }}$ galvanostatic charge-discharge curves at $1 \mathrm{~A} \mathrm{~g} \mathrm{~g}^{-1}$, (c) specific capacities of $\mathrm{Co}_{\mathrm{x}} \mathrm{Ni}_{1-\mathrm{x}}(\mathrm{OH})_{2}-\mathrm{rGO}$ composite electrodes with different initial $\mathrm{Co}$ (II) to $\mathrm{Ni}$ (II) ratios using $1.5 \mathrm{~mL}$ of hydrous hydrazine. (d) $5^{\text {th }}$ galvanostatic chargedischarge curves at $1 \mathrm{~A} \mathrm{~g} \mathrm{~g}^{-1}$, and (e) rate performance of as-prepared samples using different amounts of hydrous hydrazine: CNOH1:1, CNOH1:1-II, and CNOH1:1-III, the inset in (e) is discharge curves of the CNOH1:1-III electrode at different current densities (1-20 $\left.\mathrm{A} \mathrm{g}^{-1}\right)$, the rectangular triangles shown in the figure are used for clearly understanding the different slopes of the curves at 1 (red) and $20 \mathrm{~A} \mathrm{~g}^{-1}$ (violet). (f) Cycling performance of the CNOH1:1-III electrode at $20 \mathrm{~A} \mathrm{~g}^{-1}$. 
behaviors are consistent with the $\mathrm{CV}$ results. The corresponding discharge capacities were summarized in Figure 3c. The capacities of the $\mathrm{CNOH} 2: 1$ and $\mathrm{CNOH} 1: 1$ electrodes were similar, demonstrating 692 and $707 \mathrm{C} \mathrm{g}^{-1}$ (based on the total mass of $\mathrm{Co}_{\mathrm{x}} \mathrm{Ni}_{1-\mathrm{x}}(\mathrm{OH})_{2}-\mathrm{rGO}$ composite), respectively, much better than those of the $\mathrm{CNOH} 1: 2, \mathrm{CNOH} 3: 0$ and $\mathrm{CNOH0:3}$ electrodes. The substitution of Ni with an appropriate amount of cobalt definitely increased the specific capacity, consistent with the reported results $[25,51,55]$. Based on the slightly higher capacity and higher redox potentials (better for hybrid device) of $\mathrm{CNOH} 1: 1$ electrode compared to those of $\mathrm{CNOH} 2: 1$ electrode, the initial $\mathrm{Co}(\mathrm{II})$ to $\mathrm{Ni}(\mathrm{II})$ ratio of 1:1 was selected to study the effect of the amounts of hydrous hydrazine.

The galvanostatic charge-discharge curves of the CNOH1:1, CNOH1:1-II, and CNOH1:1-III electrodes at $1 \mathrm{~A} \mathrm{~g}^{-1}$ are shown in Figure $3 \mathrm{~d}$. The different potential plateaus suggest the difference of Co to $\mathrm{Ni}$ ratio in these samples, which was consistent with EDX analysis (Table S1). The corresponding typical rate capability results are summarized in Figure 3d. With increasing amount of hydrous hydrazine, the capacities at low current density were somewhat increased due to the increased content of $\mathrm{Co}_{\mathrm{x}} \mathrm{Ni}_{1-\mathrm{x}}(\mathrm{OH})_{2}$ in the composite. The rate capability was also enhanced with increasing amount of hydrous hydrazine. This effect is likely due to the improved microstructures of $\mathrm{CNOH} 1: 1-\mathrm{II}$ and $\mathrm{CNOH} 1: 1-\mathrm{III}$ samples, where more open channels promote easy ion access whereas the graphene allows fast current collection. In particular, specific capacities of 743 and $545 \mathrm{C} \mathrm{g}^{-1}$ were achieved, respectively, at $1 \mathrm{~A} \mathrm{~g}^{-1}$ and 20 $\mathrm{A} \mathrm{g}^{-1}$ for the CNOH1:1-III electrode. For comparison, a CNOH1:1-III sample without graphene was also prepared in a similar fashion with typical electrochemical performance shown in Figure S13. The CNOH1:1-III electrode exhibited significantly improved specific capacity and rate 
performance compared to that of the CNOH1:1-III without graphene electrode, suggesting the presence of a synergistic effect of $\mathrm{Co}_{\mathrm{x}} \mathrm{Ni}_{1-\mathrm{x}}(\mathrm{OH})_{2}$ and graphene in the composite.

Figure 3e shows the typical discharge curves of the CNOH1:1-III electrode at different current densities ( 1 to $20 \mathrm{~A} \mathrm{~g}^{-1}$ ). A potential plateau between 0.15 and $0.05 \mathrm{~V}$ with relatively small slope prevails over a wide capacity range, although the slope increased with increasing current density, suggesting an increase in the contribution of capacitive behavior to capacity. A high capacitive contribution is more beneficial to cycling stability [56,57]. When evaluated at 20 $\mathrm{A} \mathrm{g}^{-1}$, the $\mathrm{CNOH} 1: 1-\mathrm{III}$ electrode demonstrated an attractive capacity retention of $\sim 91 \%$ after 5,000 cycles (Figure 3f). The morphology stability of $\mathrm{Co}_{\mathrm{x}} \mathrm{Ni}_{1-\mathrm{x}}(\mathrm{OH})_{2}$ disks in the $\mathrm{CNOH} 1: 1-\mathrm{III}$ electrode was verified by SEM observation of $\mathrm{Co}_{\mathrm{x}} \mathrm{Ni}_{1-\mathrm{x}}(\mathrm{OH})_{2}$ disks grown on nickel foam before and after 5,000 cycles (Figure S14). Additionally, the Co:Ni ratio in the sample was found to be a key factor for cycling stability; the composite sample with a Co:Ni ratio of $\sim 2: 1$ had a better electrochemical stability compared to that of the composite sample with a Co:Ni ratio of $\sim 1: 1$ (Figure S15). The high specific capacity, rate capability, and superior cycling stability could be attributed to the proper $\mathrm{Co}: \mathrm{Ni}$ ratio, unique porous disk-like architecture, the wrapped rGO, and the high contribution of capacitive behavior to capacity at high current densities.

To further enhance the energy density, the operation voltage of the capacitor should be broadened using a hybrid cell configuration. We built a hybrid device using a high-performance $\mathrm{PPD} / \mathrm{rGO}$ composite as the negative electrode and the $\mathrm{CNOH} 1: 1-\mathrm{III}$ as the positive electrode, as schematically illustrated in Figure 1. Some typical CV curves of the two electrodes are presented in Figure 4a. Clearly, the CNOH1:1-III electrode exhibited a pair of redox peaks within a potential window of $-0.15 \sim 0.45 \mathrm{~V}$ whereas the $\mathrm{PPD} / \mathrm{rGO}$ electrode showed a typical capacitive behavior between -1.15 and $-0.15 \mathrm{~V}$ (Figure $4 \mathrm{a}$ and S16) with electrical double-layer capacitive 
contribution from rGO and amine groups-derived pseudocapacitive contribution from PPD. The $\mathrm{PPD} / \mathrm{rGO}$ composite achieved a much higher specific capacitance than that of the pure rGO sample (Figure S16). Since the specific surface area of PPD/rGO is $7.7 \mathrm{~m}^{2} \mathrm{~g}^{-1}$ and that of rGO is $188.7 \mathrm{~m}^{2} \mathrm{~g}^{-1}$ (Figure $\mathrm{S} 17$ ), the PPD in the PPD/rGO composite contributes the most to the pseudocapacitance of the sample. However, a comparison of the CV curve of pure rGO with that of the PPD/rGO electrode at the same scan rate (Figure S16) indicates that the double-layer contribution from $\mathrm{PPD} / \mathrm{rGO}$ electrode was still higher than that from pure rGO electrode, suggesting that the PPD also functions as a molecular spacer to prevent the graphene sheets from restacking. An operation voltage of $1.6 \mathrm{~V}$ could be achieved for the hybrid
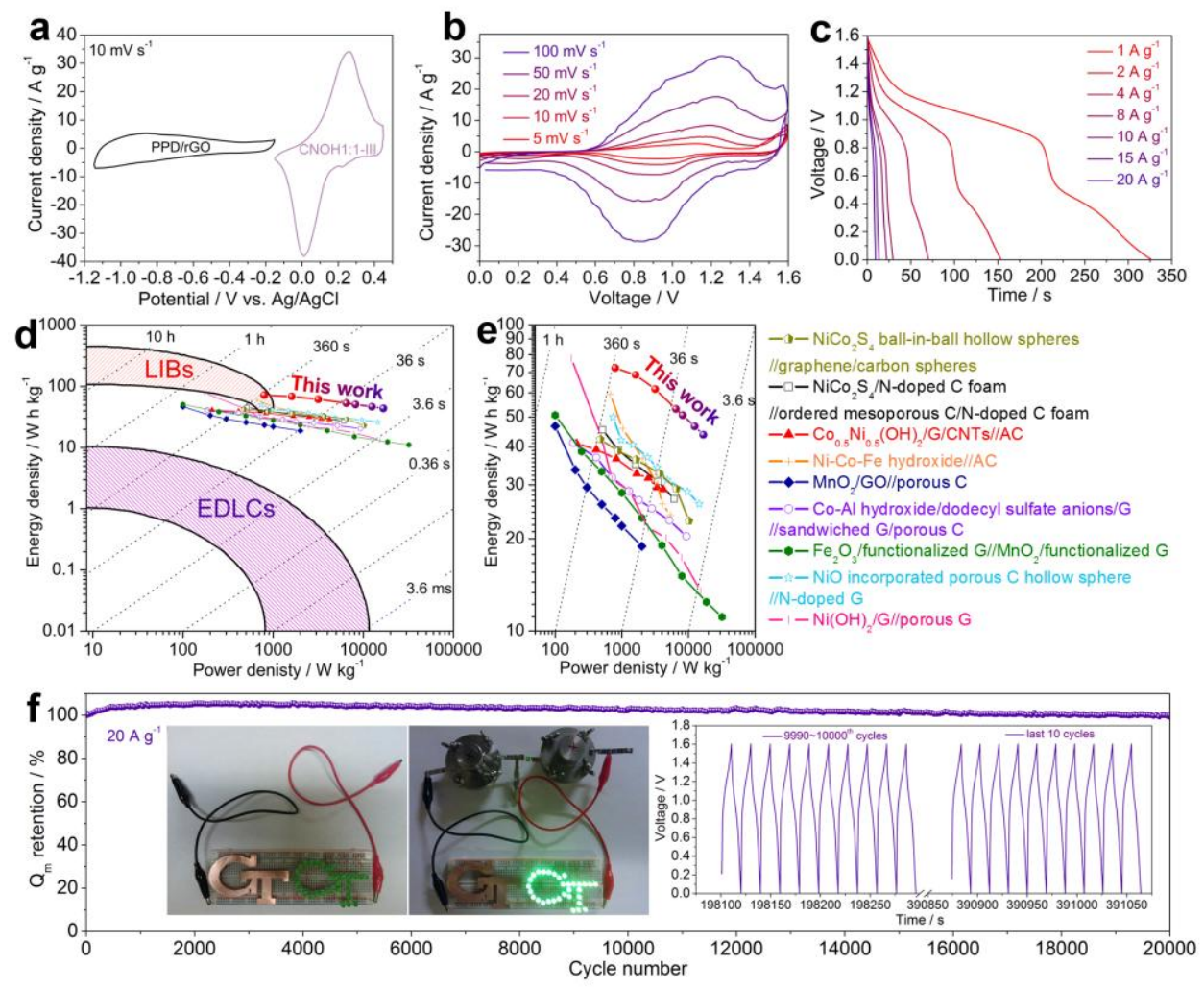

Figure 4. (a) $\mathrm{CV}$ curves of the $\mathrm{CNOH} 1: 1-\mathrm{III}$ electrode and $\mathrm{PPD} / \mathrm{rGO}$ electrode at a scan rate of $10 \mathrm{mV} \mathrm{s}^{-1}$ obtained in a three-electrode system; (b) CV curves at different scan rates $(5-100 \mathrm{mV}$ $\left.\mathrm{s}^{-1}\right)$, (c) galvanostatic discharge curves at different current densities (1-20 $\mathrm{A} \mathrm{g}^{-1}$ ) of hybrid 
supercapacitor device with CNOH1:1-III//PPD/rGO couple; (d, e) Ragone plot of the CNOH1:1III//PPD/rGO hybrid supercapacitor device compared to that of traditional EDLCs and LIBs based on the mass of active materials [34], and recently reported advanced hybrid/asymmetric supercpacitors [22-25, 45-49] with electrode materials shown in (e); all the energy/power density was calculated based on the mass of active materials; The inset time is obtained by dividing the energy density by the power density, which is a time constant of the devices; (e) is an enlarged image of (d); and (f) cycling stability at current density of $20 \mathrm{~A} \mathrm{~g}^{-1}$ between 0 and $1.6 \mathrm{~V}$ of the $\mathrm{CNOH} 1: 1-\mathrm{III} / \mathrm{PPD} / \mathrm{rGO}$ hybrid supercapacitor device, the inset shows the corresponding galvanostatic charge/discharge curves of the $9990-10000^{\text {th }}$ and last 10 cycles; the inset digital photo is a GT logo consisting of 32 green LEDs in parallel powered by two hybrid supercapacitor devices in series.

supercapacitor. The corresponding CV curves and galvanostatic discharge curves of the hybrid supercapacitor are shown in Figure $4 \mathrm{~b}$ and $4 \mathrm{c}$. The shapes of CV curves were well maintained as the scan rate was increased from 5 to $100 \mathrm{mV} \mathrm{s}^{-1}$, suggesting reasonably high rate capability of the hybrid supercapacitor, attributed to the electrochemical properties of both the positive and negative electrodes. The galvanostatic discharge curves of the hybrid supercapacitor (Figure 4c) appear to be battery-type with a marked sloping plateau at low current densities, but seems to be capacitor-like behavior at high current densities (inset in Figure 4f). The rate performance was summarized in Figure S18.

Shown in Figure 4d and 4e (the Ragone plot) are the gravimetric energy and power densities of the hybrid supercapacitor calculated from the discharge curves (Figure 4c), demonstrating a high energy density of $72 \mathrm{~W} \mathrm{~h} \mathrm{~kg}^{-1}$ at a power density of $797 \mathrm{~W} \mathrm{~kg}^{-1}$. Even at a 
power density of $16.7 \mathrm{~kW} \mathrm{~kg}^{-1}$, energy density of $44 \mathrm{~W} \mathrm{~h} \mathrm{~kg}^{-1}$ still remains. The energy and power densities of the traditional EDLCs and lithium-ion batteries (LIBs) based on the mass of active materials [34] were also presented in Figure $4 \mathrm{~d}$ for comparison. The hybrid supercapacitor delivered much higher energy density compared to that of EDLCs at the same power density and much higher power density compared to that of LIBs at the same energy density. The energy densities of the hybrid supercapacitor are comparable to those of the LIBs at the same power density. Furthermore, the gravimetric energy and power densities of the hybrid supercapacitor were superior to that of recently reported advanced hybrid/asymmetric supercapacitors, including $\mathrm{NiCo}_{2} \mathrm{~S}_{4}$ ball-in-ball hollow spheres//graphene/carbon spheres [45], $\mathrm{NiCo}_{2} \mathrm{~S}_{4} / \mathrm{N}$-doped carbon (C) foam//ordered mesoporous $\quad$ C/N-doped $\quad$ C $\quad$ foam[46], $\mathrm{Co}_{0.5} \mathrm{Ni}_{0.5}(\mathrm{OH})_{2} /$ graphene(G)/CNTs//activated carbon (AC)[25], Ni-Co-Fe hydroxide//AC[22], $\mathrm{MnO}_{2} / \mathrm{GO} / /$ porous C[47], Co-Al hydroxide/dodecyl sulfate anions/G//sandwiched G/porous C[48], $\mathrm{Fe}_{2} \mathrm{O}_{3}$ /functionalized $\mathrm{G} / \mathrm{MnO}_{2}$ /functionalized G[49], NiO-porous $\mathrm{C}$ hollow sphere//Ndoped $\mathrm{G}[23], \mathrm{Ni}(\mathrm{OH})_{2} / \mathrm{G} / /$ porous $\mathrm{G}[24]$. Additionally, the volumetric energy and power densities of the presented hybrid supercapacitor were also evaluated with results shown in Figure S19, which were comparable or even superior to that of recently reported advanced hybrid/asymmetric supercapacitors [6,33]. Moreover, a simple application example of the hybrid supercapacitor is presented. A GT (Georgia Institute of Technology) logo consisting of 32 green LEDs in parallel can be powered by two hybrid supercapacitor devices in series after being charged to $3.2 \mathrm{~V}$ (inset in Figure 4f). Cycling performance, which is an important property for a supercapacitor, of the hybrid supercapacitor at $20 \mathrm{~A} \mathrm{~g}^{-1}$ between 0 and $1.6 \mathrm{~V}$ is shown in Figure 4f. An excellent cycling stability without undergoing decay compared to the initial $\mathrm{Q}_{\mathrm{m}}$ was achieved even after 20,000 cycles at a high current density of $20 \mathrm{~A} \mathrm{~g}^{-1}$, which is much better than 
that of LIBs and superior to those of recently reported advanced hybrid/asymmetric supercapacitors (Table S2)[22-24, 45-49]. The corresponding Coulombic efficiency was around $99 \%$ for the initial 2,000 cycles, and was above $99 \%$ (close to 100\%) for the subsequent 18,000 cycles (Figure S20). Furthermore, the corresponding galvanostatic charge/discharge curves of the $9990-10000^{\text {th }}$ and the last 10 cycles are given in Figure 4f (inset). There is little observable change in these curves, confirming the excellent cycling stability of the hybrid supercapacitor.

\section{Conclusion}

In summary, a high-energy, long cycle-life hybrid supercapacitor was constructed using graphene-based hybrid materials: $\mathrm{Co}_{\mathrm{x}} \mathrm{Ni}_{1-\mathrm{x}}(\mathrm{OH})_{2}-\mathrm{rGO}$ and $\mathrm{PPD} / \mathrm{rGO}$. We have successfully prepared a series of $\mathrm{Co}_{\mathrm{x}} \mathrm{Ni}_{1-\mathrm{x}}(\mathrm{OH})_{2}-\mathrm{rGO}$ nanocomposites via a facile hydrazine-induced process and studied the effect of different $\mathrm{Co}(\mathrm{II})$ to $\mathrm{Ni}$ (II) ratios and hydrous hydrazine amounts on the phase structure, microstructure, and the electrochemical performance. In particular, a porous $\mathrm{Co}_{\mathrm{x}} \mathrm{Ni}_{1-\mathrm{x}}(\mathrm{OH})_{2}$ disks@rGO nanocomposite delivered outstanding specific capacities, rate capability, and cycling stability. When coupled with a capacitive-type PPD/rGO electrode, the hybrid supercapacitor achieved superior energy and power density, and a stable cycling performance for 20,000 cycles at $20 \mathrm{~A} \mathrm{~g}^{-1}$. The attractive electrochemical performance and simple preparation process make the hybrid supercapacitor a promising candidate for commercial applications. Furthermore, the unique architecture with porous micrometer-sized disks wrapped by rGO provides new insight into the design of better electrode materials. The facile preparation strategy further opens a general avenue to the development of cost-effective fabrication of high-performance supercapacitors based on transition metal hydroxides for many applications. 


\section{Supporting Information.}

SEM images and XRD patterns of CNOHa:b; SEM, TEM images, $\mathrm{N}_{2}$ adsorption-desorption results, TGA curves, XPS spectra and Raman results of CNOH1:1, -II, -III samples; CV curves of blank $\mathrm{Ni}$ foam; electrochemical performance of CNOH1:1-III without graphene; microstructure stability of $\mathrm{CNOH} 1: 1-\mathrm{III}$; cycling performance of the $\mathrm{CNOH} 2: 1, \mathrm{CNOH} 1: 1$, CNOH1:1-II; $\mathrm{CV}$ curves and rate performances of $\mathrm{PPD} / \mathrm{rGO}$ and pure $\mathrm{rGO}$; volumetric energy/power density of the CNOH1:1-III//PPD/rGO device; EDX analysis of $\mathrm{Co}_{\mathrm{x}} \mathrm{Ni}_{1-\mathrm{x}}(\mathrm{OH})_{2^{-}}$ rGO; comparison of the cycling stability of the supercapacitors.

\section{ACKNOWLEDGMENT}

This work was supported by the US Department of Energy ARPA-E Program under award number DE-AR0000303 and by the US National Science Foundation under award number DMR-1410320.

\section{REFERENCES}

[1] P. Simon, Y. Gogotsi, Nat. Mater., 7 (2008) 845-854.

[2] P. Simon, Y. Gogotsi, B. Dunn, Science, 343 (2014) 1210-1211.

[3] C. Zhong, Y.D. Deng, W.B. Hu, J.L. Qiao, L. Zhang, J.J. Zhang, Chem. Soc. Rev., 44 (2015) 7484-7539.

[4] Y.M. Sun, R.B. Sills, X.L. Hu, Z.W. Seh, X. Xiao, H.H. Xui, W. Luo, H.Y. Jin, Y. Xin, T.Q.

Li, Z.L. Zhang, J. Zhou, W. Cai, Y.H. Huang, Y. Cui, Nano Lett., 15 (2015) 3899-3906.

[5] G. Yu, L. Hu, M. Vosgueritchian, H. Wang, X. Xie, J.R. McDonough, X. Cui, Y. Cui, Z. Bao, Nano Lett., 11 (2011) 2905-2911. 
[6] Y. Zeng, Y. Han, Y. Zhao, Y. Zeng, M. Yu, Y. Liu, H. Tang, Y. Tong, X. Lu, Adv. Energy Mater., 5 (2015) 1402176.

[7] Y.F. Ma, H.C. Chang, M. Zhang, Y.S. Chen, Adv. Mater., 27 (2015) 5296-5308.

[8] B.T. Zhao, R. Ran, M.L. Liu, Z.P. Shao, Mat. Sci. Eng., R., 98 (2015) 1-71.

[9] F. Bonaccorso, L. Colombo, G.H. Yu, M. Stoller, V. Tozzini, A.C. Ferrari, R.S. Ruoff, V. Pellegrini, Science, 347 (2015) 1246501.

[10] M. Yang, Y.R. Zhong, J.J. Ren, X.L. Zhou, J.P. Wei, Z. Zhou, Adv. Energy Mater., 5 (2015) 1500550.

[11] E. Lim, C. Jo, H. Kim, M.H. Kim, Y. Mun, J. Chun, Y. Ye, J. Hwang, K.S. Ha, K.C. Roh, K. Kang, S. Yoon, J. Lee, ACS Nano, 9 (2015) 7497-7505.

[12] Y. Cai, B.T. Zhao, J. Wang, Z.P. Shao, J. Power Sources, 253 (2014) 80-89.

[13] H. Kim, M.Y. Cho, M.H. Kim, K.Y. Park, H. Gwon, Y. Lee, K.C. Roh, K. Kang, Adv. Energy Mater., 3 (2013) 1500-1506.

[14] A. Le Comte, T. Brousse, D. Belanger, J. Power Sources, 326 (2016) 702-710.

[15] F. Zhang, T.F. Zhang, X. Yang, L. Zhang, K. Leng, Y. Huang, Y.S. Chen, Energy Environ. Sci., 6 (2013) 1623-1632.

[16] Y.G. Wang, D.D. Zhou, D. Zhao, M.Y. Hou, C.X. Wang, Y.Y. Xia, J. Electrochem. Soc., 160 (2013) A98-A104.

[17] C.D. Gu, X. Ge, X.L. Wang, J.P. Tu, J. Mater. Chem. A, 3 (2015) 14228-14238.

[18] T.W. Lin, M.C. Hsiao, S.W. Chou, H.H. Shen, J.Y. Lin, J. Electrochem. Soc., 162 (2015) A1493-A1499.

[19] T. Brousse, D. Belanger, J.W. Long, J. Electrochem. Soc., 162 (2015) A5185-A5189.

[20] W.G. Pell, B.E. Conway, J. Power Sources, 136 (2004) 334-345. 
[21] Q. Abbas, P. Babuchowska, E. Frckowiak, F. Beguin, J. Power Sources, 326 (2016) 652659.

[22] H.B. Li, Y.Q. Gao, C.X. Wang, G.W. Yang, Adv. Energy Mater., 5 (2015) 1401767.

[23] S.Y. Kim, H.M. Jeong, J.H. Kwon, I.W. Ock, W.H. Suh, G.D. Stucky, J.K. Kang, Energy Environ. Sci., 8 (2015) 188-194.

[24] J. Yan, Z.J. Fan, W. Sun, G.Q. Ning, T. Wei, Q. Zhang, R.F. Zhang, L.J. Zhi, F. Wei, Adv. Funct. Mater., 22 (2012) 2632-2641.

[25] Y.W. Cheng, H.B. Zhang, C.V. Varanasi, J. Liu, Energy Environ. Sci., 6 (2013) 3314-3321.

[26] H.L. Wang, H.S. Casalongue, Y.Y. Liang, H.J. Dai, J. Am. Chem. Soc., 132 (2010) 74727477.

[27] L. Huang, D.C. Chen, Y. Ding, S. Feng, Z.L. Wang, M.L. Liu, Nano Lett., 13 (2013) 31353139.

[28] H. Chen, L.F. Hu, M. Chen, Y. Yan, L.M. Wu, Adv. Funct. Mater., 24 (2014) 934-942.

[29] V. Augustyn, P. Simon, B. Dunn, Energy Environ. Sci., 7 (2014) 1597-1614.

[30] Q. Mahmood, S.K. Park, K.D. Kwon, S.J. Chang, J.Y. Hong, G.Z. Shen, Y.M. Jung, T.J.

Park, S.W. Khang, W.S. Kim, J. Kong, H.S. Park, Adv. Energy Mater., 6 (2016) 1501115.

[31] Q. Mahmood, M.G. Kim, S. Yun, S.M. Bak, X.Q. Yang, H.S. Shin, W.S. Kim, P.V. Braun, H.S. Park, Nano Lett., 15 (2015) 2269-2277.

[32] Y. Gogotsi, ACS Nano, 8 (2014) 5369-5371.

[33] C. Zhou, Y.W. Zhang, Y.Y. Li, J.P. Liu, Nano Lett., 13 (2013) 2078-2085.

[34] L.B. Qu, Y.L. Zhao, A.M. Khan, C.H. Han, K.M. Hercule, M.Y. Yan, X.Y. Liu, W. Chen, D.D. Wang, Z.Y. Cai, W.W. Xu, K.N. Zhao, X.L. Zheng, L.Q. Mai, Nano Lett., 15 (2015) 20372044. 
[35] X.H. Xiong, D. Ding, D.C. Chen, G. Waller, Y.F. Bu, Z.X. Wang, M.L. Liu, Nano Energy, $11(2015)$ 154-161.

[36] P.G. Campbell, M.D. Merrill, B.C. Wood, E. Montalvo, M.A. Worsley, T.F. Baumann, J. Biener, J. Mater. Chem. A, 2 (2014) 17764-17770.

[37] Y. Zhao, J. Liu, Y. Hu, H.H. Cheng, C.G. Hu, C.C. Jiang, L. Jiang, A.Y. Cao, L.T. Qu, Adv. Mater., 25 (2013) 591-595.

[38] X.T. Zhang, Z.Y. Sui, B. Xu, S.F. Yue, Y.J. Luo, W.C. Zhan, B. Liu, J. Mater. Chem., 21 (2011) 6494-6497.

[39] M.A. Worsley, P.J. Pauzauskie, T.Y. Olson, J. Biener, J.H. Satcher, T.F. Baumann, J. Am. Chem. Soc., 132 (2010) 14067-14069.

[40] B. Song, L.Y. Li, Z.Y. Lin, Z.K. Wu, K.S. Moon, C.P. Wong, Nano Energy, 16 (2015) 470478.

[41] B. Song, C. Sizemore, L.Y. Li, X.G. Huang, Z.Y. Lin, K.S. Moon, C.P. Wong, J. Mater. Chem. A, 3 (2015) 21789-21796.

[42] H.L. Wang, Y.Y. Liang, T. Mirfakhrai, Z. Chen, H.S. Casalongue, H.J. Dai, Nano Res., 4 (2011) 729-736.

[43] W.C. Jiang, D.S. Yu, Q. Zhang, K.L. Goh, L. Wei, Y.L. Yong, R.R. Jiang, J. Wei, Y. Chen, Adv. Funct. Mater., 25 (2015) 1063-1073.

[44] L.F. Shen, L. Yu, X.Y. Yu, X.G. Zhang, X.W. Lou, Angew. Chem. Int. Ed., 54 (2015) 1868-1872.

[45] L. Shen, L. Yu, H.B. Wu, X.-Y. Yu, X. Zhang, X.W. Lou, Nat. Commun., 6 (2015) 6694. [46] L.F. Shen, J. Wang, G.Y. Xu, H.S. Li, H. Dou, X.G. Zhang, Adv. Energy Mater., 5 (2015) 1400977. 
[47] Y.F. Zhao, W. Ran, J. He, Y.Z. Huang, Z.F. Liu, W. Liu, Y.F. Tang, L. Zhang, D.W. Gao, F.M. Gao, Small, 11 (2015) 1310-1319.

[48] X.L. Wu, L.L. Jiang, C.L. Long, T. Wei, Z.J. Fan, Adv. Funct. Mater., 25 (2015) 16481655.

[49] H. Xia, C.Y. Hong, B. Li, B. Zhao, Z.X. Lin, M.B. Zheng, S.V. Savilov, S.M. Aldoshin, Adv. Funct. Mater., 25 (2015) 627-635.

[50] X.N. Lu, L.Y. Li, B. Song, K. Moon, N. Hu, G.L. Liao, T.L. Shi, C.P. Wong, Nano Energy, 17 (2015) 160-170.

[51] Z.A. Hu, Y.L. Xie, Y.M. Wang, H.Y. Wu, Y.Y. Yang, Z.Y. Zhang, Electrochim. Acta, 54 (2009) 2737-2741.

[52] J.B. Liang, R.Z. Ma, N.B.O. Iyi, Y. Ebina, K. Takada, T. Sasaki, Chem. Mater., 22 (2010) $371-378$.

[53] J.W. Lee, T. Ahn, D. Soundararajan, J.M. Ko, J.D. Kim, Chem. Commun., 47 (2011) 63056307.

[54] J.F. Moulder, W.F. Sticlke, P.E. Sobol, K.D. Bomben, Handbook of X-ray Photoelectron Spectroscopy, Perkin-Elmer Corporation, Eden Prairie, Minnesota, 1992.

[55] L.J. Xie, Z.A. Hu, C.X. Lv, G.H. Sun, J.L. Wang, Y.Q. Li, H.W. He, J. Wang, K.X. Li, Electrochim. Acta, 78 (2012) 205-211.

[56] B.T. Zhao, Z.P. Shao, J. Phys. Chem. C, 116 (2012) 17440-17447.

[57] B.T. Zhao, S.M. Jiang, C. Su, R. Cai, R. Ran, M.O. Tade, Z.P. Shao, J. Mater. Chem. A, 1 (2013) 12310-12320. 


\section{Graphical Abstract}

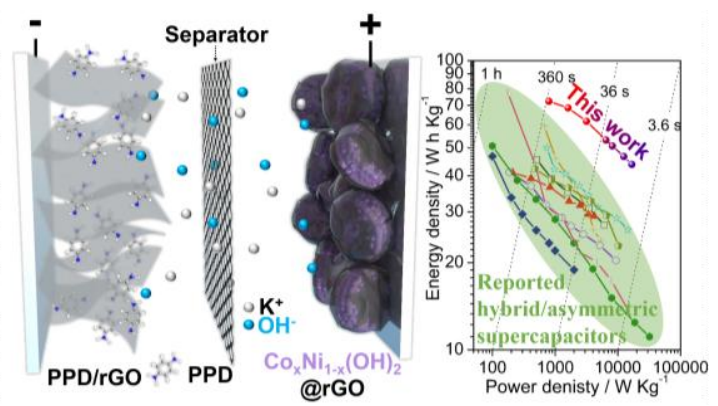

